\title{
The effect of heat stress on the survival of the rose grain aphid, Metopolophium dirhodum (Hemiptera: Aphididae)
}

\author{
Chun-Sen MA ${ }^{1,2}$, Bernhard HAU ${ }^{1}$ and Hans-Michael POEHLING ${ }^{1}$ \\ ${ }^{1}$ Institute of Plant Diseases and Plant Protection, University Hannover, Herrenhaeuser Str. 2, D-30419 Hannover, Germany; \\ e-mail: poehling@ipp.uni-hannover.de \\ ${ }^{2}$ Institute of Agricultural Environment and Sustainable Development, Chinese Academy of Agricultural Sciences, \\ Zhong-Guan-Cun South Street No. 12,100081 Beijing, China; e-mail: ma_chunsen@cjac.org.cn
}

Key words. Metopolophium dirhodum, high temperature, survival, dropping off, global warming

\begin{abstract}
The rose grain aphid, Metopolophium dirhodum (Walker) (Hemiptera: Aphididae) is one of the three most important cereal aphid species in Europe. High temperature is detrimental for the survival of this species. Detailed experiments were conducted on the effect of high temperature $\left(27,28,29,30,31,31.5,32.5,33\right.$ and $\left.34^{\circ} \mathrm{C}\right)$, period of exposure $(2,3,4,6$ and $8 \mathrm{~h}$ per day for 1,2 , 4, 6 days) and developmental stage (2nd, 3rd, 4th instar nymph and adult) on the survival of the aphid. The results show that all three factors significantly affect survival. Temperatures over $29^{\circ} \mathrm{C}$ for $8 \mathrm{~h}$ significantly reduced survival, which decreased generally as the temperature increased. The survival was inversely related to the period of exposure. Exposing aphids to $32.5^{\circ} \mathrm{C}$ for $4 \mathrm{~h}$ or longer significantly reduced survival. Mature aphids had a lower tolerance of high temperatures than nymphs. Periods of high temperature experienced by 4th instar and adult aphids can greatly affect their survival. The value of these results for forecasting and determining control thresholds, the effect of global warming on cereal aphid abundance and the dropping off behaviour of the aphids are discussed.
\end{abstract}

\section{INTRODUCTION}

In many years, the rose grain aphid, Metopolophium dirhodum (Walker) is the most abundant of the three cereal aphid species in Germany (Gräpel, 1982; Ohnesorge, 1988; Niehoff, 1996) and central European countries (Honěk, 1991).

Temperature is one of several key-factors in the population development of M. dirhodum (Dean, 1974; Zhou \& Carter, 1992). High temperature is reported to play a detrimental role in the population development of $M$. dirhodum. Honěk (1985) found that the peak density of $M$. dirhodum was negatively related to the number of days on which daily maximum temperatures exceeded $27^{\circ} \mathrm{C}$. Based on an analysis of aphid density data and weather conditions, Chen et al. (1994) suggested that the low density of $M$. dirhodum in Beijing, China, was due to high temperatures.

The survival of $M$. dirhodum at different constant temperatures was tested under laboratory conditions. A constant temperature of $30^{\circ} \mathrm{C}$ reduced the survival of aphids to zero (Dean, 1974; Zhou \& Carter, 1992). Moreover, Botto et al. (1980) reported that the offspring died in the $3 \mathrm{rd}$ instar when reared at $27^{\circ} \mathrm{C}$. However, temperature fluctuates in the field, particularly between day and night. Weather data from the German Weather Service for Göttingen and Hannover showed that during MayAugust in 1991-1996 the daily average temperatures were lower than $25^{\circ} \mathrm{C}$. However, daily average temperatures around $20-25^{\circ} \mathrm{C}$ were often associated with maximum temperatures exceeding $30^{\circ} \mathrm{C}$. Different period of exposure to high temperature $\left(27-33^{\circ} \mathrm{C}\right)$ significantly influences the reproduction and longevity of aphids (Ma et al., 2004). In order to accurately determine the population development of this aphid in the field, detailed experiments were conducted to assess the effect of different period of high temperature on the survival of the aphid.

\section{MATERIAL AND METHODS}

\section{Host plants}

Spring wheat seeds, cv "Remus" were sown in $12 \mathrm{~cm}$ diameter pots, with 13-17 seedlings per pot. These plants were grown on in a greenhouse until the first two to three leaves were fully expanded, and then used for the stock culture of aphids or for experiments.

\section{Stock culture of $M$. dirhodum}

The aphids were reared on plants in a cage $(90 \times 60 \times 60 \mathrm{~cm})$. Standard rearing conditions were a constant temperature of $20^{\circ} \mathrm{C}$ and photoperiod of $16 \mathrm{~L}: 8 \mathrm{D}$. Wheat seedlings were replaced every two weeks.

\section{Test insects}

According to Zhou \& Carter (1992), the developmental time of 1 st, $2 \mathrm{nd}$ and $3 \mathrm{rd}$ instar nymphs of $M$. dirhodum at $20^{\circ} \mathrm{C}$ is about two days for each stage, whereas 4th instar nymphs require about $61 \mathrm{~h}$. Synchronised development of the stages of $M$. dirhodum was obtained as follows: depending on the developmental stage to be tested, approximately 8.5, 6, 4 and 2 days before the start of the experiments, adults from the stock culture were placed in clip cages $(4 \mathrm{~cm}$ diameter $\times 2.5 \mathrm{~cm}$ height $)$, using a fine camel-hair brush. Three aphids were placed in each clip cage, and the cages were clipped to a leaf of a plant and supported by two bamboo sticks. Ca. $12 \mathrm{~h}$ later, the adults were removed and the newly born first instar nymphs were transferred to a clean clip cage and reared until used in the respective experiments. The synchronously developed adults were used in the first two experiments, to determine their subsequent survival after 1) $8 \mathrm{~h}$ of exposure to different high temperatures, or 2) $32.5^{\circ} \mathrm{C}$ for different periods. The developmentally-synchronised 2nd, 3rd, 4th instar nymphs and adults were used in an experiment in which their subsequent survival was determined after different period of exposure to different high temperatures. 


\section{Experimental protocol}

Test 1: Effect of high temperatures

Adults were transferred from the stock culture to clip cages. Ten adult individuals were put in each clip cage, and five clip cages, with total of 50 individuals, were put on the wheat seedlings in each pot. One hour later, pots of seedlings with clip caged adults were placed in the growth cabinets in which the temperature was set at either $27,28,29,30,31,31.5,32.5,33$ or $34^{\circ} \mathrm{C}$, respectively. After $8 \mathrm{~h}$, the pots were moved from the growth cabinets to the standard rearing room and $24 \mathrm{~h}$ later the survival of the aphids was assessed by examining them under a microscope and recorded. The temperatures in the growth cabinets were recorded using miniature data loggers (Gemini Dataloggers Ltd., UK). The temperature variation at each temperature was approximately $\pm 1^{\circ} \mathrm{C}$, relative humidity was maintained by water plates and fluctuated between 70 and $85 \%$, and the photoperiod was $16 \mathrm{~L}: 8 \mathrm{D}$.

Test 2: Effect of different periods of exposure to high temperature

As in test 1 , ten adults were put in each clip cage, and five clip cages with 50 individuals on the plants in each pot. One hour later, these pots were placed in the growth cabinets at $32.5^{\circ} \mathrm{C}$. The aphids were kept at this temperature for $2,3,4,6$ or $8 \mathrm{~h}$ for a day; or $8 \mathrm{~h}$ per day for 2, 3, 4 or 5 days, respectively. When not being exposed to a particular temperature, the pots were moved from the growth cabinets to the rearing room (constant $20^{\circ} \mathrm{C}$ ). After a particular treatment the aphids were kept in the rearing room for a further $24 \mathrm{~h}$, before the number of live and dead individuals were counted under a microscope and recorded.

Test 3: Integrated effect of temperature, period of exposure and stage of development of the aphids

Test 3 included three factors: temperature $(27,29,31$ and $33^{\circ} \mathrm{C}$ ), period of exposure ( $8 \mathrm{~h}$ per day for $1,2,4,6$ days) and developmental stage of the aphids (2nd, 3rd, 4th instar nymph and adult). Second, third, fourth instar nymphs and adults from the stock culture were clip caged separately. Ten individuals of the same stage were put in each clip cage, and there were five clip cages with a total of 50 individuals on the seedlings in each pot. The pots of plants with clip cages were distributed between the growth cabinets and kept at a particular high temperature for eight hours. The pots of plants were then moved to the rearing room and kept at $20^{\circ} \mathrm{C}$ (for $16 \mathrm{~h}$ ) for the rest of each day. This was repeated for 1, 2, 4, or 6 days. After the treatments were completed the pots of plants were kept for $24 \mathrm{~h}$ in the rearing room. The numbers of live and dead individuals were counted under a microscope.

\section{Statistical analysis}

Since test 1 and test 2 were balanced single-factor experiments, an ANOVA procedure was used to analyse the effect of high temperature and period of exposure on survival, and a Waller-Duncan K-ratio $\mathrm{T}$ test that of different high temperatures and periods of exposure (SAS Institute Inc., 1996).

For test 3, the effect of high temperature, developmental stage, period of exposure and the interactions, i.e. three first order and one second order interaction on the survival of the aphids were separately analysed using the general linear model procedure (GLM) in SAS (SAS Institute Inc., 1996). The significance $(\mathrm{P} \leq 0.05)$ of the interactions was judged from the results of the above analysis. The analysis should follow different ways for significant and non-significant interactions.

For significant interactions, for example, if survival was significantly affected by the interaction of temperature and devel-

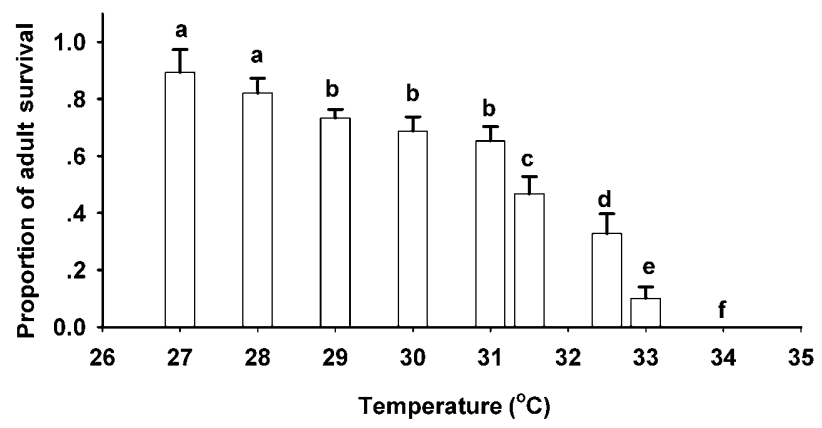

Fig. 1. Means and standard errors of the proportions of adult M. dirhodum that survived after exposure to different high temperatures for eight hours. Different letters above each bar indicate a significant difference based on Waller-Duncan K-ratio $\mathrm{T}$ test $(\mathrm{K}$-ratio $=100$ Critical Value of $\mathrm{T}=1.890$ Minimum Significant Difference $=0.082$ ).

opmental stage, one of the temperatures, e.g. $29^{\circ} \mathrm{C}$, was fixed, the survival after different period of exposure pooled and multiple comparisons (LSMEANS) made to compare the differences between development stages at $29^{\circ} \mathrm{C}$. Similar multiple comparisons were done for each factor that showed significant interactions. If the interactions were not significant, the effect of each treatment on survival was compared using multiple comparisons based on adjusted least-square means (LSMEANS) and the Tukey-Kramer method (SAS Institute Inc., 1996).

\section{RESULTS}

\section{The effect of temperature on survival}

In general, high temperatures significantly reduced survival of adult aphids $(\mathrm{F}=106.45, \mathrm{df}=(8,18), \mathrm{P}<0.001)$. Results format the Waller-Duncan K-ratio T test are illustrated in Fig. 1. When the temperature increased from 27 to $31{ }^{\circ} \mathrm{C}$ and the period of exposure kept at eight hours, the mean proportion of adults that survived fell from 89 to $65 \%$. At temperatures over $31^{\circ} \mathrm{C}$ survival declined dramatically and significantly between temperatures with $90 \%$ dying at $33^{\circ} \mathrm{C}$. All adults died in the $34^{\circ} \mathrm{C}$ treatment.

\section{The effects of periods of exposure to high temperature on survival}

The results of the analysis of variance indicated that the different period of exposure to $32.5^{\circ} \mathrm{C}$ differentially affected the

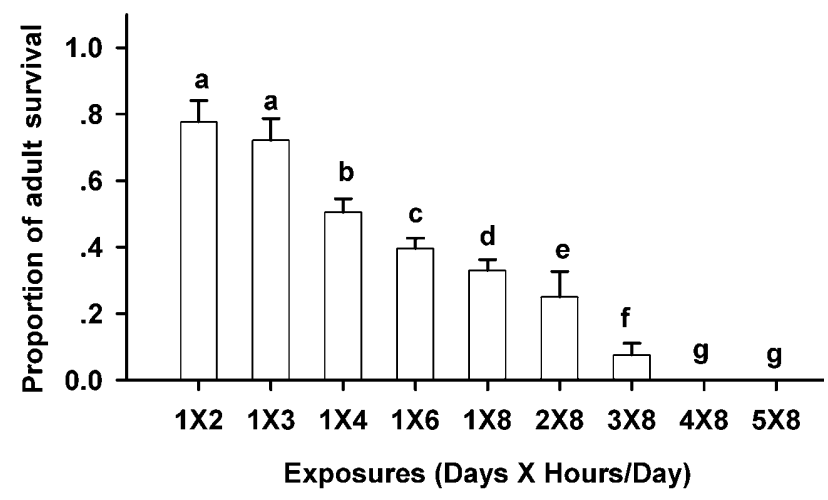

Fig. 2. Means and standard errors of the proportions of adult $M$. dirhodum that survived after exposure to $32.5^{\circ} \mathrm{C}$ for different periods. Different letters above each bar indicate a significant difference based on Waller-Duncan K-ratio $\mathrm{T}$ test $(\mathrm{K}$-ratio $=$ 100 Critical Value of $\mathrm{T}=1.871$ Minimum Significant Difference $=0.066$ ). 
TABLE 1. Mean proportions of M. dirhodum that survived after exposure of different developmental stages to high temperatures for varying periods.

\begin{tabular}{|c|c|c|c|c|c|c|c|c|c|}
\hline \multicolumn{2}{|c|}{ Temperature conditions } & \multicolumn{8}{|c|}{ Proportion that survived } \\
\hline \multirow{2}{*}{$\begin{array}{l}\text { Temp. } \\
\left({ }^{\circ} \mathrm{C}\right)\end{array}$} & \multirow{2}{*}{$\begin{array}{c}\text { Exposures } \\
\text { days } \times \text { hour/day }\end{array}$} & \multicolumn{2}{|c|}{ Adult } & \multicolumn{2}{|c|}{ 4th instar } & \multicolumn{2}{|c|}{ 3rd instar } & \multicolumn{2}{|c|}{ 2nd instar } \\
\hline & & $\bar{X}^{\mathrm{a}}$ & SE & $\bar{X}$ & SE & $\bar{X}$ & SE & $\bar{X}$ & SE \\
\hline 33 & $1 \times 8$ & 0.10 & 0.12 & 0.60 & 0.28 & 0.90 & 0.12 & 0.60 & 0.00 \\
\hline 33 & $2 \times 8$ & 0.10 & 0.12 & 0.45 & 0.41 & 0.65 & 0.30 & 0.45 & 0.25 \\
\hline 31 & $1 \times 8$ & 0.75 & 0.10 & 0.85 & 0.19 & 1.00 & 0.00 & 0.67 & 0.12 \\
\hline 31 & $2 \times 8$ & 0.75 & 0.10 & 0.75 & 0.25 & 0.80 & 0.00 & 0.40 & 0.20 \\
\hline 31 & $4 \times 8$ & 0.20 & 0.16 & 0.25 & 0.19 & 0.70 & 0.12 & 0.60 & 0.28 \\
\hline 31 & $6 \times 8$ & 0.05 & 0.10 & 0.15 & 0.19 & 0.30 & 0.26 & 0.50 & 0.26 \\
\hline 29 & $1 \times 8$ & 0.80 & 0.00 & 1.00 & 0.00 & 1.00 & 0.00 & 1.00 & 0.00 \\
\hline 29 & $2 \times 8$ & 0.80 & 0.28 & 0.90 & 0.14 & 1.00 & 0.00 & 0.80 & 0.28 \\
\hline 29 & $4 \times 8$ & 0.40 & 0.00 & 0.70 & 0.14 & 1.00 & 0.00 & 1.00 & 0.00 \\
\hline 29 & $6 \times 8$ & 0.30 & 0.14 & 0.70 & 0.14 & 0.70 & 0.14 & 0.90 & 0.14 \\
\hline 27 & $1 \times 8$ & 0.90 & 0.14 & 1.00 & 0.00 & 1.00 & 0.00 & 0.90 & 0.14 \\
\hline 27 & $2 \times 8$ & 0.80 & 0.00 & 0.90 & 0.14 & 1.00 & 0.00 & 1.00 & 0.00 \\
\hline 27 & $4 \times 8$ & - & - & 0.90 & 0.14 & - & - & - & - \\
\hline 27 & $6 \times 8$ & - & - & 0.80 & 0.00 & - & - & - & - \\
\hline
\end{tabular}

a, $\bar{X}$ and SE are the means and standard errors of the means, respectively; - , data not collected.

survival of the adult aphids $(\mathrm{F}=127.74, \mathrm{df}=(8,21), \mathrm{P}<0.001)$. The Waller-Duncan K-ratio $\mathrm{T}$ tests of survival results are presented in Fig. 2. The mean proportion that survived decreased with increase in the period of exposure to $32.5^{\circ} \mathrm{C}$. The survival of adults exposed for two and three hours did not differ significantly. However, when the period of exposure exceeded four hours survival significantly decreased with increase in the period of exposure, with $90 \%$ dying after exposure to $32.5^{\circ} \mathrm{C}$ for eight hours per day for three days. All the adult aphids died when exposed for eight hours per day for longer than 4 days.

\section{The integrated effect of temperature, period of exposure and} development stage of aphid on survival

Survival of $M$. dirhodum varied depending on the developmental stage of the aphid and the period for which they were exposed to the high temperatures (Table 1). Analysis of variance revealed that survival was significantly affected not only by these three factors but also by the interaction between aphid stage of development and the other two factors (Table 2). Therefore, the survival after different stages of the aphid were exposed were compared for each temperature and period of exposure, respectively.

\section{The effect of temperature and aphid stage of development on survival}

The interaction effects of the various high temperature regimes and aphid stages of development on the average survival of $M$. dirhodum are given in Table 3. As in test 1, survival decreased as the temperature increased. The multiple comparisons revealed all stages of development survived similarly at $27^{\circ} \mathrm{C}$ but not at the other temperatures. Compared to the nymph stages adults had a lower survival. After high temperature treatment, more 3rd instar nymphs survived than of the other stages at all temperatures although this effect was significant only when the temperature reached $31^{\circ} \mathrm{C}$. The survival of 2 nd instar and 4 th instar nymphs were similar at all temperatures. The results indicate that adults are more sensitive to high temperature than nymphs.

\section{The effect of period of exposure time and aphid stage on sur-} vival

Generally, adult aphids had a significantly lower survival than the immature aphids. This tendency was especially marked when the period of exposure was more than $8 \mathrm{~h}$ per day for 4 days. The survival of 3rd instar nymphs was highest, followed by that of the second and fourth nymphal instars, and lowest for adults, when the period of exposure was less than 4 days $8 \mathrm{~h}$ per day (Table 4).

\section{DISCUSSION}

M. dirhodum die before they reach the adult stage if reared at constant temperatures in excess of $30^{\circ} \mathrm{C}$ (Dean, 1974; Zhou \& Carter, 1992). The intrinsic rate of increase of this aphid reared at constant temperatures increases with temperature up to $25^{\circ} \mathrm{C}$ (Zhou \& Carter, 1992). However, the field data of Niehoff

TABLE 2. Analysis of variance of the effect of high temperature, period of exposure and aphid developmental stage on the survival of $M$. dirhodum.

\begin{tabular}{lccrcc}
\hline Source & SS & MS & F & df & P \\
\hline Temp & 3.88 & 1.30 & 38.28 & 3 & 0.0001 \\
Expose & 3.20 & 1.07 & 31.57 & 3 & 0.0001 \\
Temp $\times$ Expose & 0.49 & 0.07 & 2.06 & 7 & 0.0551 \\
Stage & 2.45 & 0.82 & 24.12 & 3 & 0.0001 \\
Temp $\times$ Stage & 0.75 & 0.08 & 2.46 & 9 & 0.0144 \\
Expose $\times$ Stage & 1.38 & 0.15 & 4.53 & 9 & 0.0001 \\
Temp $\times$ Expose $\times$ Stage & 0.20 & 0.01 & 0.39 & 15 & 0.9797 \\
Error & 3.25 & 0.03 & & 96 & \\
Total & 15.59 & & & 145 & \\
\hline
\end{tabular}

$\mathrm{SS}$, represents sum of squares; MS, represents mean sum of squares. 
TABLE 3. Multiple comparisons of the proportions of $M$. dirhodum that survived after different developmental stages of the aphid were exposed to different temperatures.

\begin{tabular}{lllll}
\hline Temp & $27^{\circ} \mathrm{C}(\mathrm{LSM})$ & $29^{\circ} \mathrm{C}(\mathrm{LSM})$ & $31^{\circ} \mathrm{C}(\mathrm{LSM})$ & $33^{\circ} \mathrm{C}(\mathrm{LSM})$ \\
\hline 2nd instar nymph & $0.950 \pm 0.04 \mathrm{a}$ & $0.925 \pm 0.05 \mathrm{a}$ & $0.541 \pm 0.05 \mathrm{a}$ & $0.525 \pm 0.08 \mathrm{a}$ \\
3rd instar nymph & $1.000 \pm 0.04 \mathrm{a}$ & $0.925 \pm 0.05 \mathrm{a}$ & $0.700 \pm 0.05 \mathrm{~b}$ & $0.775 \pm 0.08 \mathrm{a}$ \\
4th instar nymph & $0.950 \pm 0.04 \mathrm{a}$ & $0.825 \pm 0.05 \mathrm{a}$ & $0.500 \pm 0.05 \mathrm{a}$ & $0.525 \pm 0.08 \mathrm{a}$ \\
Adult & $0.850 \pm 0.04 \mathrm{a}$ & $0.575 \pm 0.05 \mathrm{~b}$ & $0.437 \pm 0.05 \mathrm{a}$ & $0.100 \pm 0.08 \mathrm{~b}$ \\
\hline
\end{tabular}

LSM, represents the adjusted least square means; the LSM of the proportions surviving followed by different letters within columns are different at $\mathrm{P}=0.05$. the LSM for 27 and $33^{\circ} \mathrm{C}$ were obtained after exposure for one or two days, for eight hours per day.

(1996) indicate that $M$. dirhodum can survive a daily maximum temperature of $30^{\circ} \mathrm{C}$ on winter wheat, and the aphid population collapses if the daily average temperature reaches $22.2-24.8^{\circ} \mathrm{C}$ for one week. According to the German Weather Service, the daily average temperature rarely reaches $25^{\circ} \mathrm{C}$, but the daily maximum temperature often exceeds $30^{\circ} \mathrm{C}$ during the period of aphid infestation. Our results showed that not only the temperature but also the period for which it was high had a significant effect on the aphid survival. The survival of the adults was as high as 69 and $33 \%$ at 30 and $32.5^{\circ} \mathrm{C}$ respectively, when the period of exposure was $8 \mathrm{~h}$ (Figs 1,2). A constant daily temperature of $25^{\circ} \mathrm{C}$ is equivalent to $35^{\circ} \mathrm{C}$ for $8 \mathrm{~h}$ and $20^{\circ} \mathrm{C}$ for $16 \mathrm{~h}$ each day $[(35 \times 8+20 \times 16) /(8+16)=25]$. Our results indicate that no adults survive after they were exposed to $34^{\circ} \mathrm{C}$ for $8 \mathrm{~h}$ (Fig. 1). The population development observed in the field can be explained using the results we obtained rearing aphids under temperature conditions comparable to those recorded in the field.

Fourth instar nymphs and adults of $M$. dirhodum possibly avoid unfavourable temperatures by moving onto the lower parts of the plants. M. dirhodum usually feed on the lower leaves (Dedryver, 1989). However, the proportion of M. dirhodum on the flag leaf varied from year to year in northern Germany. In years with high daily maximum temperatures during the period of the aphid infestation, the proportion of aphids on the flag leaves was low $(30 \%)$. In years when daily maximum temperatures were comparatively low, the proportion on the flag leaves increased to 54-60\% (Niehoff, 1996). M. dirhodum may also avoid unfavourable temperatures by dropping off plants. Results of one of our preliminary laboratory experiments indicate that most adult and fourth instar nymphs drop from plants onto the soil when placed in a growth chamber at $33^{\circ} \mathrm{C}$. One hour later, when these aphids were returned to $20^{\circ} \mathrm{C}$, they immediately climbed back up onto the plants. Since moist soil heats up more slowly than air, aphids might reduce the detrimental effects of high temperatures by moving onto the soil surface. Thus in the field, aphids might avoid the heat by occupying the lower parts of their host plants and/or moving onto the surface of moist soil in the shade. However, the surface temperature of dry soil $\left(43-52^{\circ} \mathrm{C}\right)$ is much higher than that of the air temperature $\left(28^{\circ} \mathrm{C}\right)$ in the afternoon in Hannover, northern Germany. The pea aphid, Acyrthosiphon pisum, is less likely to drop off its host plant when conditions are hot and dry than when more benign (Dill et al., 1990). Thus, this drop behaviour of aphids might be related to soil moisture.

Effects of periods of high temperature on $M$. dirhodum could affect the control threshold. The official threshold for spraying insecticides to control cereal aphids in Germany is four aphids per ear and/or flag-leaf at the end of flowering (Niehoff \& Staeblein, 1998). As discussed above, matured aphids avoid heat stress by moving to the lower parts of plants or dropping onto moist ground. Therefore, the best decisions are likely to be those based on field samples taken in the morning before high temperatures occur. In warm regions, field sampling should record not only the number of aphids per ear and flag leaf but also those on the lower leaves.

In addition, the field data of Niehoff (1996), show that in Göttingen in 1991, although there were more than four aphid/ear and or flag leaf at the end of flowering, the aphid population did not reach a high density but collapsed immediately at the beginning of the watery ripe stage due to the stress of 11 days of daily maximum temperatures of $26-32.4^{\circ} \mathrm{C}$. The weight of thousand grains did not differ significantly between unsprayed and sprayed plots, which indicates that insecticide spraying was not necessary. Therefore, when the daily maximum temperatures exceed $27^{\circ} \mathrm{C}$, our results for aphid survival (Figs 1, 2 and Table 1) and reproduction (Ma et al., 2004) should be born in mind when deciding whether to apply insecticide.

Periods of high temperature can affect aphid forecasts. Using hourly average temperatures, and the results from constant temperature experiments (Dean, 1974; Zhou \& Carter, 1992) underestimates the survival of aphids, because the temperatures at 12:00-14:00 are often over $30^{\circ} \mathrm{C}$ and at this temperature all aphids die. Using average daily temperatures (Dean, 1974; Zhou \& Carter, 1992), leads to an over-estimate of aphid survival because they hardly ever reach $25^{\circ} \mathrm{C}$ and the detrimental effect of maximum temperatures over $30^{\circ} \mathrm{C}$ are ignored. Incorporating the data in Table 1 and that on reproduction and longevity in Ma et al. (2004) in a population simulation model for M. dirhodum resulted in very accurate population forecasts $(\mathrm{Ma}, 2000)$. When the effect of high maximum temperatures are not incorporated in the simulation model, the predicted population densities (Sim_Sum) for 9 fields in northern Germany (Goettingen 1991, 1992, 1993; Hiddesdorf 1991, 1992; Grossenwieden 1992; Ruth

TABLE 4. Multiple comparisons of the proportions of $M$. dirhodum that survived after different developmental stages of the aphid were exposed to high temperatures for eight hours for 1 to 6 days.

\begin{tabular}{lllll}
\hline Temp & $1 * 8(\mathrm{LSM})$ & $2 * 8(\mathrm{LSM})$ & $4 * 8$ (LSM) & $6 * 8$ (LSM) \\
\hline 2nd instar nymph & $0.792 \pm 0.04 \mathrm{a}$ & $0.663 \pm 0.07 \mathrm{a}$ & $0.800 \pm 0.08 \mathrm{a}$ & $0.700 \pm 0.09 \mathrm{a}$ \\
3rd instar nymph & $0.975 \pm 0.04 \mathrm{~b}$ & $0.863 \pm 0.07 \mathrm{a}$ & $0.850 \pm 0.08 \mathrm{a}$ & $0.500 \pm 0.09 \mathrm{~b}$ \\
4th instar nymph & $0.862 \pm 0.04 \mathrm{ab}$ & $0.750 \pm 0.07 \mathrm{a}$ & $0.475 \pm 0.08 \mathrm{~b}$ & $0.425 \pm 0.09 \mathrm{~b}$ \\
Adult & $0.638 \pm 0.04 \mathrm{c}$ & $0.613 \pm 0.07 \mathrm{a}$ & $0.300 \pm 0.08 \mathrm{~b}$ & $0.175 \pm 0.09 \mathrm{~b}$ \\
\hline
\end{tabular}

LSM, represents the adjusted least square means; the LSM of the proportions surviving followed by different letters within columns are different at $\mathrm{P}=0.05$. The LSM are for exposures of 4 and 6 days $\left(8 \mathrm{~h}\right.$ per day) of 31 and $29^{\circ} \mathrm{C}$. 
1994 1995 1996) were overestimated: Sim Sum = $11.612+1.3 \times$ Obs_Sum (Obs_Sum is the observed population density). Although the regression is significant ( $\mathrm{df}=75,2 ; \mathrm{F}=$ 91.42), the mean corrected R-square (1-Residual/Corrected) was only 0.582 . In the contrast, when the effect of high maximum temperatures on survival and reproduction in M. dirhodum was incorporated in the simulation model, its accuracy was greatly improved: Sim_Sum $=0.356+1.059 \times$ Obs_Sum $(\mathrm{df}=75,2 ; \mathrm{F}=$ 656.8). The mean corrected R-square was as high as 0.928 . Removing the effect of MaxT led to a population increase of $45 \%$.

According to the National Academy of Sciences, the Earth's surface temperature has risen by about $0.6^{\circ} \mathrm{C}$ in the past century, with accelerated warming during the past two decades. The 20th century's 10 warmest years all occurred in the last 15 years of the century. The average global surface temperature could rise $0.6-2.5^{\circ} \mathrm{C}$ in the next fifty years, and $1.4-5.8^{\circ} \mathrm{C}$ in the next century (US Environment Protection Agency, 2004). Our results indicated that $M$. dirhodum is a highly temperature sensitive species. Global warming may play a role in the long-term changes in the population abundance of M. dirhodum. Ma (2000) did a sensitivity analysis of the effect of temperature increase on the population abundance of $M$. dirhodum. The predicted population density for a field in Göttingen in 1992 was very close to that observed. If the daily average temperature (TX) increases by $1^{\circ} \mathrm{C}$ the maximum daily temperature (MaxT) increases by $1.3^{\circ} \mathrm{C}$ (MaxT $=1.29 \mathrm{TX}$, adjusted $\left.\mathrm{R}^{2}=0.996\right)$ in northern Germany (Ma, 2000). An increase in TX of $1^{\circ} \mathrm{C}$ and MaxT of $1.3^{\circ} \mathrm{C}$ during the main period of the aphid population increase would result in a $33 \%$ reduction in peak population size. An increase in TX of $2^{\circ} \mathrm{C}$ and MaxT of $2.6^{\circ} \mathrm{C}$ would result in an early population collapse ( $74 \%$ reduction of population size).

ACKNOWLEDGEMENTS. We thank M. Fiebig and M. Galler for supplying the aphids and wheat seeds for the stock culture. We are grateful to F. Bretz and M. Weichert in the Bioinformatics Laboratory for their advice on statistical analysis.

\section{REFERENCES}

Botto E.N. \& Boggiatto de Pacheco M.E. 1980: Resultados preliminares de estudios bioecologicos sobre el "pulgon amarillo de los cereales" Metopolophium dirhodum (Walker), realizado en Castelar, Bs. As. durante 1976 a 1979. II. Estudios de laboratorio. Efecto de la temperatura sobre el desarrollo de M. dirhodum (Walker). Rev. Soc. Entomol. Argent. 39: 179-188.

Chen J.L., Guo Y.Y., Ni H.X., Ding H.J., CaO Y.Z. \& Xia Y.L. 1994: Studies on the dynamics of field populations of the rose grain aphid. Acta Phytophyl. Sin. 21: 7-13 (in Chinese).
DeAn G.W.J. 1974: Effect of temperature on the cereal aphids Metopolophium dirhodum (Wlk), Rhopalosiphum padi (L.) and Macrosiphum avenae (F.) (Hem., Aphididae). Bull. Entomol. Res. 63: 401-409.

DeDRYver C.A. 1989: A twelve year study of cereal aphids on winter wheat in Brittany. Pest status of Sitobion avenae F., Metopolophium dirhodum Wlk. and Rhopalosiphum padi L. during spring. IOBC/ WPRS Bull. 12(1): 7-12.

Dill L.M., Fraser A.H.G. \& Roitberg B.D. 1990: The economics of escape behaviour in the pea aphid, Acyrthosiphon pisum. Oecologia 83: 473-478.

GRÄPEL H. 1982: Untersuchungen zum Einfluss einiger Insektizide auf natürliche Blattlausfeinde. Z. Pflanzenkrankh. Pflanzenschutz 89: 241-252.

HoNĚK A. 1985: Temperature and plant vigour influence annual variation of abundance in cereal aphids (Homoptera, Aphididae). Z. Pflanzenkrankh. Pflanzenschutz 92: 588-593.

HoNĚK A. 1991: Factors determining the peak abundance of Metopolophium dirhodum (Homoptera: Aphididae) on cereals. Bull. Entomol. Res. 81: 57-64.

MA C.S. 2000: Modelling and Simulation of the Population Dynamics of the Cereal Aphid Metopolophium dirhodum in Northern Germany. Verlag Franzbecker, Hildesheim, Berlin, pp. 85-111.

Ma C.S., Hau B. \& Poenling H.M. 2004: Effects of pattern and timing of high temperature exposure on reproduction of the rose grain aphid, Metopolophium dirhodum. Entomol. Exp. Appl. 110: 65-71.

NIEHOFF B. 1996: Untersuchungen zum Einfluß gestaffelter Aufwandmengen der Insektizide Pirimor und Karate auf die Populationsdynamik von Getreideblattläusen in Winterweizen unter besonderer Berücksichtigung von Nebenwirkungen auf ausgewählte Nutzarthropoden. Verlag Papierflieger, Clausthal Zellerfeld, 237 pp.

Niehoff B. \& Staeblein J. 1998: Comparative studies to determine the damage potential of Metopolophium dirhodum (Wlk.) and Sitobion avenae (F.) in winter wheat. IOBC/ WPRS Bull. 21(8): 21-27.

OHNESORGE B. 1988: Investigations on the population dynamics of maize aphids in southwestern Germany. Meded. Fac. Landb. Rijksuniv. Gent 53: 1187-1193.

SAS Institute Inc. 1996. SAS/STAT User's guide Volume 2, GLM-VARCOMP, Version 6.

US Environment Protection Agency 2004: Global warmingClimate. Home page of United States Environment Protection Agency. Http://yosemite.epa.gov/oar/globalwarming.

ZHOU X. \& CARTER N. 1992: Effects of temperature, feeding position and crop growth stage on the population dynamics of the rose grain aphid, Metopolophium dirhodum (Hemiptera: Aphididae). Ann. Appl. Biol. 121: 27-37.

Received September 22, 2003; revised January 23, 2004; accepted March 8, 2004 